\title{
Intraocular lens in a fighter aircraft pilot
}

\author{
Anat Loewenstein, Orna Geyer, Yoram Biger, Rivka Bracha, Igal Shochat, Moshe Lazar
}

\begin{abstract}
A pseudophakic pilot of the Israeli air force flying an F-15 (Eagle) aircraft was followed up for three years. He experienced about 100 flying hours, $5 \%$ of the time under high $g$ stress. The intraocular lens did not dislocate and no complications were observed. It seems that flying high performance fighter aircraft is not contraindicated in pseudophakic pilots.
\end{abstract}

In the past the development of cataract has ended a pilot's flying career. Aphakic glasses cause a $33 \%$ magnification of objects and a severe visual field restriction; they are thus unsuitable in the flight environment. Contact lenses have the potential complications of a foreign body in the eye and are limited by a variable ocular tolerance and wearing time. Dust and particles floating around, wind blast, possible loss, and the nuisance of removing, cleaning, and reinserting make the contact lens less than ideal for the military environment. There are few data on pseudophakic pilots. The largest series deals with 75 commercial and private pilots. ${ }^{1}$ In 1987 Mader et al reported that only eight pilots in the USA army (all of them flying helicopters) had an intraocular lens (IOL). ${ }^{2}$ To the best of our knowledge this is the first report of an IOL implantation in a pilot flying high performance fighter aircraft and exposed to high $g$ forces.

\section{Case report}

A 34-year-old F-15 (Eagle) pilot underwent an extracapsular cataract extraction ECCE+IOL (Rayner-850B) implantation in the posterior chamber in March 1988. The operation and postoperative course were uneventful. Three months after the operation the patient resumed flying and was exposed to gradually increasing acceleration forces of up to $+9 \mathrm{~g}$. Four months after the operation he returned to full flight status. During three years of follow-up the pilot experienced about 100 hours of flying the high performance fighter aircraft, $5 \%$ of the time under acceleration forces of up to $+9 \mathrm{~g}$. On the last examination the patient's uncorrected visual acuity in his right eye was $6 / 18$, and with a correction of $\left(-2 \cdot 25 /+1.5 \times 90^{\circ}\right)$ reached $6 / 4$. Stereoscopic and colour vision were undis-

\begin{tabular}{|c|c|c|c|c|}
\hline Author & Aircraft & No. & Type & Complications \\
\hline Mader $e t a l^{2}$ & Helicopter pilots & 8 & $\begin{array}{l}\text { Ant. chamber-2 } \\
\text { Post. chamber-5 } \\
\text { Iris supported-1 }\end{array}$ & $\begin{array}{l}\text { Glare, erythropsia } \\
\text { Glare, erythropsia } \\
\text { Cystoid macular oedema }\end{array}$ \\
\hline Liddy $e t a l^{\prime}$ & $\begin{array}{l}\text { Airline transport pilots } \\
\text { Commercial pilots } \\
\text { Private } \\
\text { Flight engineer }\end{array}$ & $\begin{array}{r}6 \\
5 \\
38 \\
1\end{array}$ & Not reported & Glare, altered colours \\
\hline
\end{tabular}

turbed. The IOL was well centred, lying in the capsular bag, and the posterior capsule was clear and intact. In the left eye the visual acuity was $6 / 6$, with an unaided near vision of Jaeger 1 . No complaints or difficulty in flying have been noted.

\section{Discussion}

The reported cases of IOL implantation in pilots are summarised in Table 1. The largest series is of private and commercial pilots ${ }^{1}$ in whom the main problem is loss of accommodative ability, necessitating near correction. In pilots of high performance fighter aircraft the vibration and acceleration which generate high gravitational forces cause an additional risk of IOL dislocation. To the best of our knowledge the safety of IOL implantation in high $g$ aviators has not been reported. As to hard contact lenses, it was found that a significant hazard exists owing to the risk of decentration and dislodgement from the eye. ${ }^{3}$ Soft contact lenses on the other hand were not found to be subject to decentration. ${ }^{3-7}$ On a human centrifuge Forgie and Meek $^{6}$ tested soft contact lenses up to $+6 g$ and found small amounts of decentration which they believed would not interfere with vision. Also on a human centrifuge Brennan and Girvin ${ }^{7}$ found that soft contact lenses were displaced by a maximum of $1.5 \mathrm{~mm}$ when exposed to acceleration forces of $+4 \mathrm{~g}$ and by $1.75 \mathrm{~mm}$ when exposed to $+6 g$. The decentration was more marked in soft toric lenses as a result of their heavier weight.

The effect of high $g$ stress on IOLs has been studied only in monkeys by Tredici (personal communication). He implanted them in the anterior and posterior chamber of monkeys and exposed them to $+12 \mathrm{~g}$ on a centrifuge. The IOLs did not dislocate and no complications were observed. These studies encouraged us to allow our patient to return to full flight activity.

It seems that flying high performance fighter aircraft is not contraindicated for pseudophakic pilots.

1 Liddy BSL, Boyd K, Takahashi Y. Cataracts, intra-ocular lens implants, and a flying career. Aviat Space Environ Med 1990; 61: $660-1$.

2 Mader TH, Carey WH, Friedl KE, Wilson WR. Intraocular lenses in aviators: a review of US army experience. Aviat Space Environ Med 1987; 58: 690-4.

3 Flynn WJ, Block MG, Tredici TJ, Provines WG. Effect of positive acceleration $(+\mathrm{Gz})$ on soft contact lens wear. Aviat Space Environ Med 1987; 58: 581-7.

4 Polishuk A, Raz D. Soft hydrophilic contact lenses in civil and military aviation. Aviat Space Environ Med 1975; 46: and military

5 Nilsson K, Rengstroff RH. Continuous wearing of Duragel contact lenses by Swedish Air force pilots. Am F Optom contact lenses by Swedish

6 Forgie RE, Meek LF. The movement of soft contact lenses on the human eye exposed to $+G z$ acceleration. Downsview, Canada: Defense and Civil Institute Environmental Medicine, 1980: DCIEM Report No. 80-R-49.

7 Brennan DH, Girvin JK. The flight acceptability of soft contact lenses: an environmental trial. Aviat Space Environ Med 1985; 56: 43-8. 